\title{
Do Health Reforms Impact Cost Consciousness of Health Care Professionals? Results from a Nation-Wide Survey in the Balkans
}

\author{
Mihajlo Jakovljevic ${ }^{1}$, Mira Vukovic ${ }^{2}$, Chia-Ching Chen $^{3}$, Mirjana Antunovic ${ }^{4}$, Viktorija Dragojevic-Simic ${ }^{5}$, \\ Radmila Velickovic-Radovanovic ${ }^{6}$, Mladenovic Siladji Djendji ${ }^{7}$, Nikola Jankovic ${ }^{8}$, Ana Rankovic ${ }^{9}$, Aleksandra \\ Kovacevic $^{5}$, Marko Antunovic ${ }^{4}$, Olivera Milovanovic ${ }^{10}$, Veroljub Markovic ${ }^{10}$, Babu N.S. Dasari ${ }^{11}$ Tetsuji Yamada $^{12}$
}

\author{
${ }^{1}$ Health Economics and Pharmacoeconomics, University of Kragujevac, Faculty of Medical Sciences, Kragujevac, Serbia \\ ${ }^{2}$ Department of Quality Assurance, Health Centre, Valjevo, Serbia \\ ${ }^{3}$ Department of Epidemiology \& Community Health, New York Medical College, School of Health Sciences \& Practice, New York, USA \\ ${ }^{4}$ Institute of Pharmacy, Military Medical Academy, Belgrade, Serbia \\ ${ }^{5}$ Centre for Clinical Pharmacology, Military Medical Academy, Belgrade, Serbia \\ ${ }^{6}$ Department of Pharmacy, Nis University Faculty of Medicine, Nis, Serbia \\ ${ }^{7}$ Psychiatric Clinic, University Clinical Center Vojvodina, Novi Sad, Serbia \\ ${ }^{8}$ Department of Statistics, University of Kragujevac Faculty of Medical Sciences, Kragujevac, Serbia \\ ${ }^{9}$ Diagnostic Radiology Service, University Clinical Center Kragujevac, Kragujevac, Serbia \\ ${ }^{10}$ Department of Pharmacy, University of Kragujevac Faculty of Medical Sciences, Kragujevac, Serbia \\ ${ }^{11}$ Department of Economics, Rutgers University, the State University of New Jersey, New Jersey, USA \\ ${ }^{12}$ Department of Economics, Rutgers University, the State University of New Jersey, Center for Children and Childhood Studies, New Jersey, USA
}

Background: Serbia, as the largest market of the Western Balkans, has entered socioeconomic transition with substantial delay compared to most of Eastern Europe. Its health system reform efforts were bold during the past 15 years, but their results were inconsistent in various areas. The two waves of global recession that hit Balkan economies ultimately reflected to the financial situation of healthcare. Serious difficulties in providing accessible medical care to the citizens became a reality. A large part of the unbearable expenses actually belongs to the overt prescription of pharmaceuticals and various laboratory and imaging diagnostic procedures requested by physicians. Therefore, a broad national survey was conducted at all levels of the healthcare system hierarchy to distinguish the ability of cost containment strategies to reshape clinician's mindsets and decision-making in practice.

Aims: Assessment of healthcare professionals' judgment on economic consequences of prescribed medical interventions and evaluation of responsiveness of healthcare professionals to policy measures targeted at increasing cost-consciousness.

Study Design: Cross-sectional study.
Methods: A nationwide cross-sectional survey was conducted through a hierarchy of medical facilities across diverse geographical regions before and after policy action, from January 2010 to April 2013. In the middle of the observed period, the National Health Insurance Fund (RFZO) adopted severe cost-containment measures. Independently, pharmacoeconomic guidelines targeted at prescribers were disseminated. Administration in large hospitals and community pharmacies was forced to restrict access to high budget-impact medical care. Economic Awareness of Healthcare Professionals Questionnaire-29 (EAHPQ-29), developed in Serbian language, was used in face-to-face interviews. The questionnaire documented clinician's attitudes on: Clinical-Decision-Makingbetween-Alternative-Interventions (CDMAI), Qualityof-Health-Care (QHC), and Cost-Containment-Policy (CCP). The authors randomly and anonymously recruited 2000 healthcare experts, with a total of 1487 responding; after eliminating incomplete surveys, 649 participants were considered before and 651 after policy intervention. Results: Dentists $(1.195 \pm 0.560)$ had a higher mean CDMAI score compared to physicians $(1.017 \pm 0.453)$. The

Address for Correspondence: Dr. Mihajlo Jakovljevic, Health Economics and Pharmacoeconomics, University of Kragujevac, Faculty of Medical Sciences, 
surgical group compared to the internist group had a higher total EAHPQ-29 score, CCP score and CDMAI score. Policy intervention had a statistically significant negative impact on the $\mathrm{QHC}$ score $(\mathrm{F}=4.958 ; \mathrm{df}=1 ; \mathrm{p}=0.027)$. There was no substantial impact of policy interventions on professional behavior and judgment with regard to the CDMAI, CCP, and total EAHPQ-29 scores.

Conclusion: Although cost savings were forcibly imposed in practice, the effects on clinical decision-making were modest. Clinicians' perceptions of quality of medical care were explained in a less effective manner due to the severely constrained resources allocated to the providers. This pioneering effort in the Balkans exposes the inefficiency of current policies to expand clinicians' cost consciousness. Keywords: Awareness, cost control, economics, government, health care reform, hospital costs, medical, policy, practice patterns, physicians

JEL code: I180 Health
Eastern Europe, serving as a historical stage for a unique societal experiment of socialism, exposes quite a different heritage in terms of healthcare management and funding patterns compared to the rest of Europe (1). Most of the transitional processes have been completed after two and a half decades and healthcare sectors of these countries were reshaped once again according to the market-oriented models (2).

Serbia entered into the transition essentially with a nine year delay because of the civil war and dissolution of Yugoslavia. It was the core of the most advanced socialist economy, lying outside the Iron Curtain, and therefore quite an interesting country in which to observe the Eastern European health policy challenges. With the advent of the world macroeconomic crisis in 2008, all of the Western Balkan economies experienced substantial difficulties in providing sustainable healthcare financing (3). Serbia's National Health Insurance Institute core fund, which is in charge of most of the healthcare funding and deals with the largest regional population, soon introduced costcontainment policies and financial punitive measures against over-prescribing physicians (4). In 2011, local Guidelines on Pharmacoeconomic Evaluations in Serbia were published, disseminated and implemented into clinical practice (5). During the same period, from the beginning of 2011 to the middle of 2012, hospital management staff members in the public sector throughout the country were instructed to implement severe restrictive measures, limiting resource consumption whilst not threatening maintenance and the quality of care.

A lack of clinicians' awareness on costs was recognized early as one of the major drivers of over-consumption of medical services rooted in the economic principle of "supplier-induced demand" (6). Evidence rather remains in question with the total absence of estimating cost consciousness and clinical decision-making patterns in the wide Eastern Europe region in the literature (7). The primary target of a responsible and comprehensive health policy should be the delivery of affordable, equitable and quality medical care. However, due to the effective resource limitations, even in the wealthiest societies, cost-containment remains high on the agenda as the secondary policy target. One of the most efficient approaches is increasing the economic awareness of clinical physicians as the main prescribing authority. In this way, "supplier-induced demand" could be kept to an effective minimum.

In this study, we were able to get an in-depth insight into the clinician's economic awareness and the value for money perception in their everyday work. The objectives of the study were to assess the judgments of healthcare professionals on the economic consequences of prescribed medical interventions and to evaluate the responsiveness of healthcare professionals in different healthcare policy measures aimed at cost-consciousness by the healthcare professionals. Another benefit from this study was reliable assessment of the responsiveness of clinicians' attitudes and behavior to the policy interventions.

\section{MATERIALS AND METHODS}

\section{Data}

There were 2000 anonymous questionnaires distributed among clinical physicians, dentists and pharmacists across the country. With interested parties, these formularies were completed by means of guided interviews conducted by field researchers in the hospitals or primary care facilities. Research was carried out in: (1) inpatient tertiary care (including all university centers); (2) over $50 \%$ of state facilities for secondary care intended for hospital care for at least 100,000 people; (3) over $50 \%$ of the city's institutions of primary care; and (4) a few private polyclinics. The privately-owned sector was represented by smaller facilities due to the fact that almost all medium and large hospitals were State-owned enterprises in most Western Balkans countries, with the exception of a few. These facilities were selected on a random basis from the larger pool in order to preserve the professional heterogeneity of the sample of clinicians, and provide a geographic representation of the national health system throughout the country. 


\section{Participants}

Our study encompassed all hierarchical levels of healthcare facilities dispersed across all geographical regions during the 40 month period of observation. There were two chronological cross-sections of the total Serbian population of approximately 30,500 licensed clinical physicians, 2,227 dentists and 2,130 pharmacists. The complex tripartite policy strategy implemented to reduce non-cost-effective prescribing behavior was regarded as an experimental factor whose impact was to be assessed. The sample groups ("before intervention" and "after intervention") were independent.

\section{Policy intervention}

Arising from regional difficulties in healthcare funding and growing instabilities of the health sector, we employed a three-way health policy approach to cut costs and improve the efficiency of service provision in Serbia (8). The National Health Insurance Fund (RFZO) is a core financing institution for the provision of all public and most private medical services in the country. The Fund adopted and the package of cost-containment measures, including financial sanctions for over-prescribing physicians, and introduced narrow, strictlydefined criteria for the reimbursement of medicines (4). Local Guidelines of Pharmacoeconomics targeted at prescribers and aimed to increase awareness on cost-effectiveness were developed by the Pharmaceutical Chamber of Serbia and circulated nationwide (5). The National Ministry of Health requested public hospital management staff to implement a restrictive approach toward resource consumption to achieve

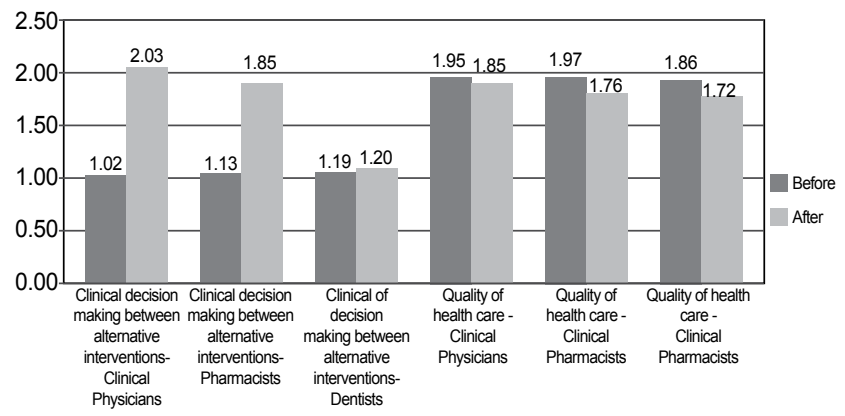

FIG. 1. Intervention effects - the total score EAHPQ-29 at particular EAHPQ-29 questionnaire domains scores in the period before and after the intervention

\section{Period}

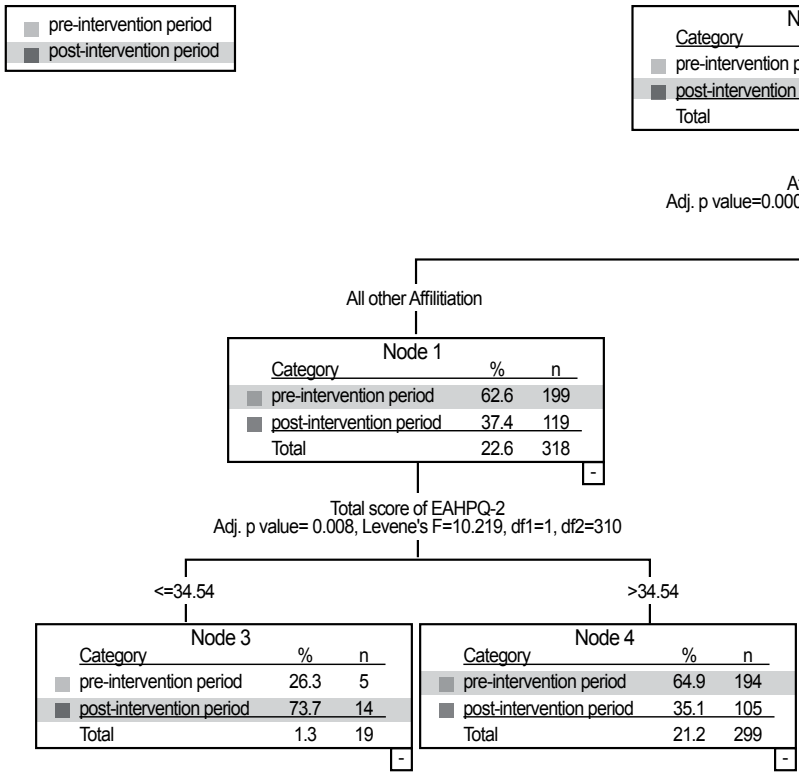

Node 0

\begin{tabular}{ccc} 
& $\%$ & $\mathrm{n}$ \\
\hline od & 46.1 & 650 \\
riod & 53.9 & 759 \\
\hline
\end{tabular}
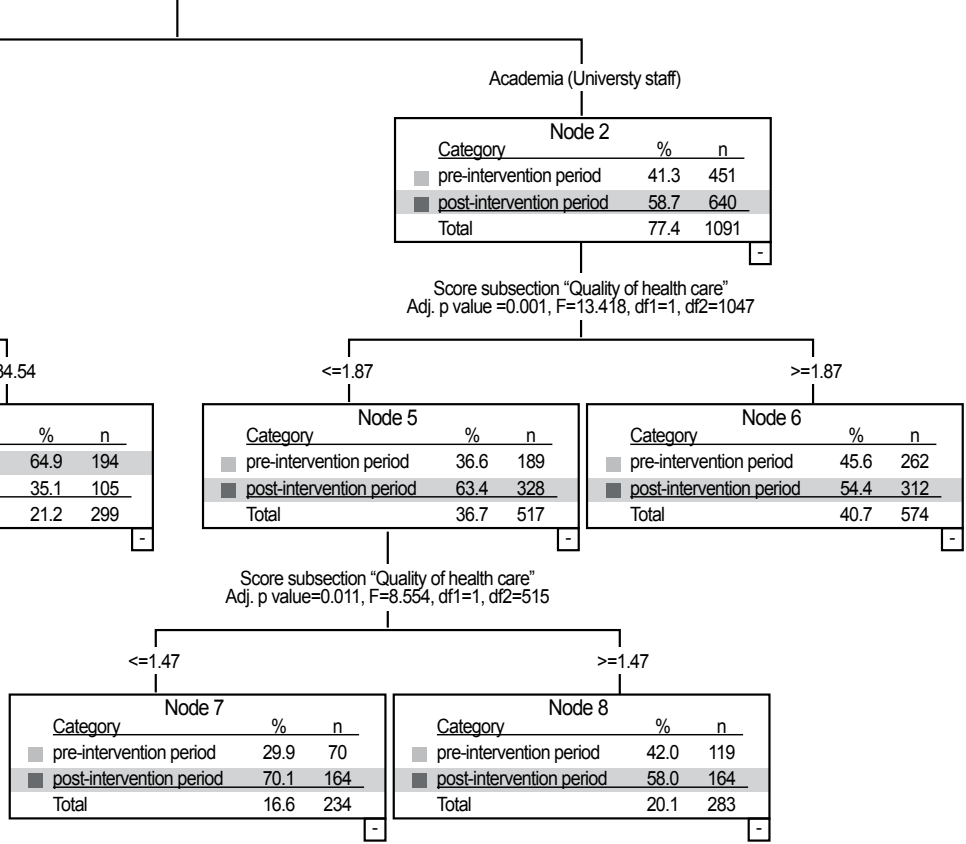

FIG. 2. Interactions between the total score of Economic Awareness of Healthcare Professionals Questionnaire - 29, domain "Quality of Health Care", and affiliation of participants on period modalities (pre-intervention/post-intervention), presented by the decision tree 
the lower level which is still sufficient to cover the current needs of the population.

\section{Survey instrument}

In the study, as a measuring instrument, the Economic Awareness of Healthcare Professional Questionnaire-29 (EAHPQ-29) was used (Appendix 1). The questions were arranged in a Likert-type ascending numerical scale from 0 ("I don't agree at all") to 5 ("I quite agree"). EAHPQ-29 represents an upgrade and extended development of another psychometric instrument that was originally developed by Skootsku and Wilkes (9) in order to assess the impact of Managed Care in the United States (US) market. The first 12 items are the original contribution of the authors in the domain of Clinical Decision-Making between Alternative Interventions (CDMAI), while the remaining items (13-29) represent adaptations of original items that have been slightly reformulated to address Eastern European policy challenges. Items 13-23 indicate the domain of Quality of Health Care (QHC), while items 24-29 define the domain of Cost Containment Policy (CCP).

\section{Timeline}

The first cross-section, through the national health system of Serbia, was initiated in January 2010 and lasted until June 2011. Then, from July 2011 until June 2012, large-scale national efforts aimed at costs savings in healthcare took place. The authors regarded these previously announced policy measures as an intervention whose effect should be assessed in practice. A one-year break was allowed for measures to be implemented and the nationwide dissemination to take place. Beginning from July 2012 until April 2013, the second cross-section through the national health system was performed. A sample of healthcare facilities was randomly selected to preserve geographic representation in both waves of the survey and also to save the comparable structure of institutions presented before and after the intervention in terms of the presence of primary, secondary and tertiary care facilities. Both the institutions and the individual participants interviewed differed between the two chronological series in the vast majority of cases. Therefore, the total duration of the study was nearly 40 months.

\section{Statistical analysis}

Calculations of mean values were made. The arithmetic mean and the standard deviation (SD) were used as measures of dispersion. The frequency distributions per category - levels of received variables of nominal character - were presented. Within the inferential statistical methods, Multivariate Analysis of Variance (MANOVA) and the decision tree methods were used. In addition, the reliability of EAHPQ-29 and its all domains was estimated with Cronbach's Alpha. MANOVA was performed to analyze the effect of interventions, medical groups, and the professionals on the Total score of EAHPQ-29 and corresponding score domains. The decision tree method was employed for analysis of the interaction between health professional affiliations and scores of the EAHPQ-29 in the period before and after the intervention (Figure 2).

QUEST was selected as the growing method, because missing values are excluded from the tree growing process but are classified using surrogates (10). A missing value of nominal independent variables was treated as a missing value. The minimum number of cases selected in the parent node was 50 , and the minimum number of cases in the child node was 10 . It also showed gains for nodes by target category. The accepted level of significance for the probability of error of the first order was 0.05 . The statistical package used for data analysis was Statistical Package for Social Science Research, version 18 (Statistical Package for Social Science Research, version 18, SPSS Inc.; Chicago, Illinois, USA).

\section{RESULTS}

In total, 1487 participants were willing to participate. The response rate was $74.35 \%$. Overall, 187 cases were eliminated due to incomplete answers, while the remaining 1300 participants were used for further analysis. Facilities from which employees were interviewed included 16 secondary hospitals, 7 tertiary care hospitals, 21 primary care facilities (including dispensing pharmacies in each one) and 7 specialized private polyclinics. In total, $49.8 \%$ of the survey was conducted before policy intervention took place, including $84.3 \%$ physicians (394 internal medicine branches, 88 surgeons), $8.8 \%$ pharmacists and $6.9 \%$ dentists, while $51.2 \%$ were interviewed after the policy intervention, of which $94.5 \%$ were physicians (360 internal medicine branches, 185 surgeons), 2.1\% were pharmacists and $3.4 \%$ were dentists. There were 1091 (77.4\%) participants with only a clinical background, while the remaining 209 (22.6\%) were affiliated with both medical care and academic institutions.

TABLE 1. Internal consistency of Economic Awareness of Healthcare Questionnaire and its domains

\begin{tabular}{lcc}
\hline Scale & Number of items & Cronbach's alpha \\
\hline EAHPQ & 29 (all items) & 0.71 \\
Domains of CDMAI & 12 & 0.78 \\
Domains of QHC & 11 & 0.75 \\
Domains of CCP & 6 & 0.65 \\
\hline
\end{tabular}

EAHPQ: Economic Awareness of Healthcare Questionnaire; CDMAI: clinical decision-making between alternative interventions; QHC: quality of health care; $\mathrm{CCP}$ : cost containment policy 
Internal consistency for EAHPQ-29 and its domains is shown in Table 1. The first MANOVA model (Table 2) showed that policy intervention had a statistically significant negative impact on QHC score $(\mathrm{F}=4.958 ; \mathrm{df}=1 ; \mathrm{p}=0.027)$, which surprisingly showed higher assessed values before the intervention compared to values after the intervention. Policy intervention proved to be without impact in two of the remaining domains CDMAI ( $\mathrm{F}=0.721 ; \mathrm{df}=1 ; \mathrm{p}=0.396), \mathrm{CCP}(\mathrm{F}=0.136$; $\mathrm{df}=1 ; \mathrm{p}=0.712)$ and the total EAHPQ-29 score $(\mathrm{F}=0.970$; $\mathrm{df}=1 ; \mathrm{p}=0.325)$. There were no significant interactions between intervention and professional background for all of the observed scores.

Although there was a significant effect of professional backgrounds on the CDMAI score (Table 2), in post hoc testing, it

TABLE 2. The total score and domain scores of Economic Awareness of Healthcare Professionals Questionnaire-29 before and after policy intervention according to professional background

\begin{tabular}{|c|c|c|c|c|c|c|}
\hline \multirow[b]{2}{*}{ Score } & \multicolumn{3}{|c|}{ Period before intervention } & \multicolumn{3}{|c|}{ Period after intervention } \\
\hline & Professional background & $\mathrm{N}$ & Mean \pm SD $(95 \% \mathrm{CI})$ & $\mathrm{N}$ & Mean \pm SD $(95 \% \mathrm{CI})$ & $\mathrm{p}(\mathrm{F} ; \mathrm{df})$ \\
\hline \multirow[t]{8}{*}{ CDMAI score } & Clinical & 546 & $1.020 \pm 0.446$ & 616 & $1.015 \pm 0.459$ & \\
\hline & Physicians & & $(0.981-1.058)$ & & $(0.979-1.051)$ & \\
\hline & Pharmacists & 57 & $1.126 \pm 0.395$ & 14 & $1.274 \pm 0.518$ & $0.001 * *$ (a) \\
\hline & & & $(1.007-1.245)$ & & $(1.034-1.514)$ & $(\mathrm{F}=7.337 ; \mathrm{df}=2)$ \\
\hline & Dentist & 45 & $1.189 \pm 0.511$ & 22 & $1.201 \pm 0.663$ & \\
\hline & & & $(1.055-1.323)$ & & $(1.009-1.392)$ & \\
\hline & Total by period & 648 & $1.040 \pm 0.449$ & 652 & $1.027 \pm 0.470$ & $0.396(b)$ \\
\hline & & & $(1.006-1.075)$ & & $(0.990-1.063)$ & $(\mathrm{F}=0.721 ; \mathrm{df}=1)$ \\
\hline \multirow[t]{8}{*}{ QHC score } & Clinical Physicians & 546 & $1.952 \pm 0.482$ & 616 & $1.850 \pm 0.538$ & \\
\hline & & & $(1.910-1.995)$ & & $(1.809-1.890)$ & \\
\hline & Pharmacists & 57 & $1.974 \pm 0.377$ & 14 & $1.760 \pm 0.0 .471$ & 0.227 (a) \\
\hline & & & $(1,842-2.107)$ & & $(1.493-2.026)$ & $(\mathrm{F}=1.486 ; \mathrm{df}=2)$ \\
\hline & Dentist & 45 & $1.855 \pm 0.395$ & 22 & $1.719 \pm 0.759$ & \\
\hline & & & $(1.706-2.003)$ & & $(1.506-1.932)$ & \\
\hline & Total by period & 648 & $1.947 \pm 0.468$ & 652 & $1.843 \pm 0.545$ & $0.026^{*}(\mathrm{~b})$ \\
\hline & & & $(1.911-1.984)$ & & $(1.801-1.885)$ & $(\mathrm{F}=4.958 ; \mathrm{df}=1)$ \\
\hline \multirow[t]{8}{*}{$\mathrm{CCP}$ score } & Clinical Physicians & 546 & $2.031 \pm 0.475$ & 616 & $1.920 \pm 0.569$ & $0.027 *$ (a) \\
\hline & & & $(1.987-2.075)$ & & $(1.879-1.962)$ & $(\mathrm{F}=3.615 ; \mathrm{df}=2)$ \\
\hline & Pharmacists & 57 & $1.839 \pm 0.433$ & 14 & $1.869 \pm 0.582$ & \\
\hline & & & $(1.702-1.976)$ & & $(1.592-2.146)$ & \\
\hline & Dentist & 45 & $2.126 \pm 0.656$ & 22 & $2.129 \pm 0.598$ & \\
\hline & & & $(1.972-2.280)$ & & $(1.908-2.350)$ & \\
\hline & Total by period & 648 & $2.020 \pm 0.482$ & 652 & $1.926 \pm 0.572$ & $0.712(b)$ \\
\hline & & & $(1.984-2.058)$ & & $(1.882-1.970)$ & $(\mathrm{F}=0.136 ; \mathrm{df}=1)$ \\
\hline \multirow[t]{8}{*}{ Total score of EAHPQ-29 } & Clinical Physicians & 546 & $45.899 \pm 8.375$ & 616 & $44.052 \pm 9.721$ & 0.262 (a) \\
\hline & & & $(45.136-46.663)$ & & $(43.333-44.771)$ & $(\mathrm{F}=1.339 ; \mathrm{df}=2)$ \\
\hline & Pharmacists & 57 & $46.263 \pm 6.988$ & 14 & $45.857 \pm 10.450$ & \\
\hline & & & $(43.900-48.626)$ & & $(41.089-50.626)$ & \\
\hline & Dentist & 45 & $47.422 \pm 9.581$ & 22 & $46.091 \pm 10.901$ & \\
\hline & & & $(44.762-50.082)$ & & $(42.287-49.895)$ & \\
\hline & Total by period & 648 & $46.037 \pm 8.349$ & 652 & $44.159 \pm 9.771$ & $0.325(b)$ \\
\hline & & & $(45.393-46.681)$ & & $(43.408-44.911)$ & $(\mathrm{F}=0.970 ; \mathrm{df}=1)$ \\
\hline
\end{tabular}

CI: confidence interval; N: number of participants; SD: standard deviation; (a): between professions; (b): between periods; *: the significance level $<0.05 ; * *$ : the significance level <0.01; F: Fisher statistic; df: degree of freedom; EAHPQ: Economic Awareness of Healthcare Questionnaire; CDMAI: clinical decision-making between alternative interventions; $\mathrm{QHC}$ : quality of health care; $\mathrm{CCP}$ : cost containment policy 
TABLE 3. Total score and domain scores of Economic Awareness of Healthcare Professionals Questionnaire - 29 depending before and after intervention according to clinical physician's group

\begin{tabular}{|c|c|c|c|c|c|c|}
\hline \multicolumn{7}{|c|}{ Period before intervention } \\
\hline Score & Professional background & $\mathrm{N}$ & Mean \pm SD $(95 \% \mathrm{CI})$ & $\mathrm{N}$ & Mean \pm SD $(95 \% \mathrm{CI})$ & $\mathrm{p}(\mathrm{F} ; \mathrm{df})$ \\
\hline \multirow[t]{6}{*}{ CDMAI score } & Internist Group & 394 & $1.017 \pm 0.472$ & 360 & $1.027 \pm 0.473$ & $0.047 *$ (a) \\
\hline & & & $(0.971-1.064)$ & & $(0.978-1.114)$ & $(\mathrm{F}=3.941 ; \mathrm{df}=1)$ \\
\hline & Surgical Group & 88 & $1.136 \pm 0.426$ & 185 & $1.046 \pm 0.477$ & \\
\hline & & & $(1.038-1.235)$ & & $(0.978-1.114)$ & \\
\hline & Total by period & 482 & $1.039 \pm 0.466$ & 545 & $1.033 \pm 0.474$ & $0.246(b)$ \\
\hline & & & $(0.997-1.080)$ & & $(0.993-1.073$ & $(\mathrm{F}=1.345 ; \mathrm{df}=1)$ \\
\hline \multirow[t]{6}{*}{ QHC score } & Internist Group & 394 & $1.918 \pm 0.491$ & 360 & $1.788 \pm 0.527$ & 0.076 (a) \\
\hline & & & (1.866-1.969) & & $(1.733-1.842)$ & $(\mathrm{F}=3.154 ; \mathrm{df}=1)$ \\
\hline & Surgical Group & 88 & $1.967 \pm 0.455$ & 185 & $1.877 \pm 0.610$ & \\
\hline & & & $(1.857-2.077)$ & & $(1.801-1.952)$ & \\
\hline & Total by period & 482 & $1.927 \pm 0.484$ & 545 & $1.818 \pm 0.560$ & $0.005^{* *}(\mathrm{~b})$ \\
\hline & & & $(1.883-1.970)$ & & $(1.770-1.865)$ & $(\mathrm{F}=7.997 ; \mathrm{df}=1)$ \\
\hline \multirow[t]{6}{*}{ CCP score } & Internist Group & 394 & $2.004 \pm 0.482$ & 360 & $1.890 \pm 0.550$ & $<0.001 * *$ (a) \\
\hline & & & $(1.963-2.055)$ & & $(1.837-1.944)$ & $\mathrm{F}=15.324 ; \mathrm{df}=1$ \\
\hline & Surgical Group & 88 & $2.142 \pm 0.450$ & 185 & $2.054 \pm 0.558$ & \\
\hline & & & $(2.034-2.250)$ & & $(1.979-2.129)$ & \\
\hline & Total by period & 482 & $2.029 \pm 0.479$ & 545 & $1.946 \pm 0.556$ & $0.009 * *(b)$ \\
\hline & & & $(1.986-2.072)$ & & $(1.899-1.993)$ & $\mathrm{F}=6.870 ; \mathrm{df}=1$ \\
\hline \multirow[t]{6}{*}{ Total score of EAHPQ-29 } & Internist Group & 394 & $45.325 \pm 9.032$ & 360 & $43.325 \pm 9.721$ & $<0.001 * *$ (a) \\
\hline & & & $(44.408-46.242)$ & & $(42.366-44.284)$ & $(\mathrm{F}=13.124 ; \mathrm{df}=1)$ \\
\hline & Surgical Group & 88 & $48.125 \pm 7.010$ & 185 & $45.519 \pm 9.451$ & \\
\hline & & & $(46.185-50.065)$ & & $(44.181-46.857)$ & \\
\hline & Total by period & 482 & $45.836 \pm 8.759$ & 545 & $44.070 \pm 9.803$ & $<0.001^{* *}(\mathrm{~b})$ \\
\hline & & & $(43.245-44.895)$ & & $(43.245-44.895)$ & $(F=11.164 ; d f=1)$ \\
\hline
\end{tabular}

was found that only dentists had higher scores compared to pharmacists $(\mathrm{p}=0.011)$, while between the other pairs of $\mathrm{CD}$ MAI score, there were no significant differences. Professional backgrounds did not significantly influence the EAHPQ-29 score or the remaining domain scores (Figure 1).

The second MANOVA model (Table 3) provided evidence of a significant physician group impact (internists/surgeons) on the total EAHPQ-29 and all domain scores, except the QHC score. The surgical group compared to the intern group had higher total EAHPQ-29, CCP and CDMAI scores. The model also showed that policy intervention impact was statistically significant in terms of reducing the total EAHPQ-29, QHC and CCP scores. In these assessments, higher scores were seen before the intervention compared to the after. There was no impact of intervention on the CDMAI domain $(\mathrm{F}=1.345 ; \mathrm{df}=1 ; \mathrm{p}=0.246)$. There were no significant interactions between intervention and physician group in all of the observed scores.
The decision tree model (Figure 2) showed several statistically significant interactions between the affiliation of health professionals and the total EAHPQ-29 score and significant interactions between affiliation and QHC score, both before and after the intervention. Rather low values $(\leq 34.54)$ of the total EAHPQ-29 score were observed among the majority $(73.7 \%)$ of health professionals without an academic affiliation, while $64.9 \%$ of these participants had paradoxically higher estimates (>34.54) before the intervention. In the population with academic affiliation, in the post-interventional period, there were significantly more frequent low $\mathrm{QHC}$ scores $\leq 1.47$ compared to the frequency of the $\mathrm{QHC}$ score $>1.47$. Through the decision tree model, there were $86.2 \%$ participants precisely classified in the post-interventional period and $29.8 \%$ participants within the pre-interventional period. The total accuracy of this classification was $60.2 \%$. Within the applied growing method, the risk \pm standard error value was $0.398 \pm 0.013$. 


\section{DISCUSSION}

An issue of cost-consciousness of nursing staff was recognized early as one of the major cost drivers of clinical care and was initially described during the 1990 s $(11,12)$. The tendency towards excessive medical spending due to insufficient economic awareness of healthcare professionals was noticed within different national settings (13-15). Nevertheless, most of the published evidence dealing with this issue was focused on the psychological background of medicine prescription $(16,17)$. Although quite manageable by different policies, drug costs in high income economies account for a rather small portion of the total direct medical costs $(18,19)$. Therefore, wider horizon scanning encompassing clinicians' awareness and attitudes on intensive care unit procedures (20), diagnostics (21), high-tech imaging (22), anesthesia (23), psychotherapy techniques (24) and rehabilitation (25) provision costs was necessary to obtain insight into the bigger picture. Our results indicate that there are both qualitative and quantitative differences in the perception of tested behavioral health economic phenomena between health professionals in academic institutions compared to health professionals from all other institutions. During the period after the intervention compared to the period before the intervention, a higher incidence of low perception of the quality of healthcare among the academic population was noticed, while the population outside academic institutions frequently showed low total scores for economic awareness. As a likely solution to cope with this important real-world cost driver, some authors recommended early prevention by the inclusion of the basics of health economics into undergraduate medical curricula (26). To the best of our knowledge, however, this is still not the case in most medical schools across the world.

The results showed that policy intervention had a statistically significant negative impact on the perception of all healthcare professional populations in terms of quality of healthcare. We also showed that the scores for clinician's perceptions about the quality of healthcare, including scores of Clinical decisionmaking between alternative interventions, were extremely low, both before and after the intervention. It also notes that our mentioned domains had greater criteria applicability of evidencebased practice, rather than beliefs, attitudes or knowledge about the strength of the connection between evidence-based practice (EBP) and quality of healthcare. On a scale from $0-100 \%$, it has been shown that there is a great difference (up to 65\%) between the healthcare professional's beliefs: "EBP is important to improve patient care quality" and healthcare professional's skills: "I possess sufficient skills to implement EBP principles" (27). We have also shown that physicians and pharmacists recognized the value of EBP to a similar extent. These findings generally coincide with the results of other studies $(28,29)$. While cost sav- ings in Serbia were forcibly imposed, the effects on clinical decision-making were rather modest. In fact, clinicians' perception of the quality of medical care even worsened due to the intervention, which can be explained by severely constrained resources being allocated to the providers. This was a pioneering effort in the wider Eastern European and Balkans region, exhibiting the essential weakness of current healthcare planning practice and the necessity for a more systematic policy approach in the future.

Contemporary momentum in the Western Balkans healthcare financing instabilities inspired us to conduct a nationwide cross-sectional survey in the largest regional market of Serbia (4). The trial's in-depth assessment of clinicians' economic judgment related to decision-making between diagnostic and/ or treatment alternatives proved that the current policy remained quite unsuccessful in terms of increasing their cost consciousness. Quite an interesting finding was the regional physicians' consideration of clinical alternatives from the economic point of view, which was rather unusual. The majority of these doctors, pharmacists and dentists did not exhibit an adequate understanding of the policy principles lying behind resource allocation science.

Important new information uncovered in this Serbian study was the fact that participants' professional background significantly correlated with attitudes, which is one piece of the puzzle that has been missing in many previous studies (18). This could ultimately allow for a different approach in educating physicians on the basic economic principles in healthcare. Other published evidence, mostly in high income settings, raised debate around public expectations with regard to costcontainment policies (30). Recognition of the relevance of inter-country comparisons and regional differences in public opinion was recognized in some of the recent findings (14).

In conclusion, this Eastern European study showed that cost containment policy measures did not substantially impact on clinician's economic awareness in practice. Two domains of the psychometric scale (attitudes towards choice between alternatives and cost containment policy) remained virtually untouched in spite of the systematic pursue of policy measures. In contrast, attitudes toward quality of care testing revealed that clinicians' perceptions indicated a decreased quality of care in the public sector after the set of interventions was introduced. Severe restrictions in services coverage and selective reimbursement decisions may be held responsible for such developments.

An objective observer might conclude that Health Technology Assessment and cost-effectiveness based decision-making still have to take root in the wider Balkans region (8). Therefore, a lower degree of economic awareness maturity among healthcare professionals and policy makers contributes to the poor effects of the recent policy shift. It seems that although cost savings were partially achieved, for a substantial change in the long-term, 
deeper reform of national health system management will be essential. It would be of utmost importance if clinical staff could be influenced to accept "value for money" assessment on medical technologies as part of their everyday decision-making process. Thus, an avoidable part of unnecessary medical consumption could be limited. In time, the likelihood of more cost-effective technologies being recommended to patients will increase and lead to wiser resource allocation. This becomes a particularly sensitive issue in middle income economies of Eastern Europe outside the European Union (EU), recently experiencing severe challenges to sustainable funding of their national health sectors. Regardless of the fact that the current policy showed modest success in reshaping clinician's mindset in the region, it should be noted that the economic awareness of clinicians should be recognized as the one of the long-term policy goals. The responsiveness of physicians, dentists and pharmacists and favorable attitudes toward cost-effective prescribing practice could be successfully built-up in years to come.

The Eastern European national health systems expose traditional scarcity of resources, underdevelopment and worse health indicators compared to Western and Central Europe (3). In a setting with the lower overall efficiency of medical services provision, policy makers should be particularly aware of how sensitive the clinicians' and pharmacists' role is with regard to delivering optimal quality of medical care in spite of financial limitations.

\section{Limitations}

There were some unavoidable methodological limitations to our study. Construct validity of the EAHPQ-29 questionnaire has not been established with appropriate Principal Components Analysis. Due to an ambitious task of making two crosssections through all levels of the national health system, sample heterogeneity needed to be as high as possible. Due to this inclusion requirement, it was difficult to avoid a certain degree of structure difference of two chronological cross-sections in terms of professional background and/or affiliating institutions of participants. Dentists and pharmacists were present to a lesser extent than doctors. However, this relationship between the aforementioned health professionals faithfully reflects the existing structure of health professionals in our healthcare system. The study did not include health professionals from smaller urban hospitals as well as smaller urban and rural primary facilities. Therefore, there might have been some bias with implications to the responses and domain scores within some subgroups of interviewed clinicians. Also, it should be noticed that most items contained within the last two domains were originally developed in English language. Although validation procedures in Serbian language were applied, some concepts such as "value for money" in healthcare were still difficult to understand by the Eastern European physicians educated purely on the "patient clinical benefit" thinking tradition. Therefore, a certain degree of answer distortion was possible due to items being misinterpreted by the physicians.

Ethics Committee Approval: N/A.

\section{Informed Consent: N/A.}

Peer-review: Externally peer-reviewed.

Author contributions: Concept - M.J., M.V., C.C.C., B.N.S.D., T.Y.; Design - M.J., M.V., C.C.C., B.D., T.Y.; Supervision - M.J., M.V., C.C.C., B.D., T.Y.; Resource - M.J., M.V., C.C.C., T.Y., M.A., V.D.S., R.V.R., M.S.D., N.J., A.R., A.K., M.A., O.M., V.M.; Data Collection \&/or Processing - M.J., M.V., C.C.C., T.Y., M.A., V.D.S., R.V.R., M.S.D., N.J., A.R., A.K., M.A., O.M., V.M.; Analysis \&/or Interpretation - M.J., M.V., C.C.C., T.Y., M.A., V.D.S., R.V.R., M.S.D., N.J., A.R., A.K., M.A., O.M., V.M.; Literature Search - M.J., M.V., C.C.C., B.N.S.D., T.Y.; Writing - M.J., M.V., C.C.C., B.N.S.D., T.Y.; Critical Reviews - M.J., M.V., C.C.C., T.Y., M.A., V.D.S., R.V.R., M.S.D., N.J., A.R., A.K., M.A., O.M., V.M., B.N.S.D., T.Y.

Conflict of Interest: No conflict of interest was declared by the authors.

Financial Disclosure: The Ministry of Education Science and Technological Development of the Republic of Serbia has funded the underlying study behind reported results through Grant OI 175014. Publication of results was not contingent to Ministry's censorship or approval.

\section{REFERENCES}

1. Waters HR, Hobart J, Forrest CB, Siemens KK, Pittman PM, Murthy A, et al. Health insurance coverage in central and Eastern Europe: trends and challenges. Health Affair (Millwood) 2008;27:478-86. [CrossRef]

2. Rechel B, McKee M. Health reform in central and eastern Europe and the former Soviet Union. Lancet 2009;374:1186-95. [CrossRef]

3. Bredenkamp C, Mendola M, Gragnolati M. Catastrophic and impoverishing effects of health expenditure: new evidence from the Western Balkans. Health Policy Plann 2011;26:349-56. [CrossRef]

4. Jakovljevic M, Jovanovic M, Lazic Z, Jakovljević V, Đukić A, Velicković R, et al. Current efforts and proposals to reduce healthcare costs in Serbia. SJECR 2011;12:161-3. [CrossRef]

5. Novakovic T, Tesic D, Stefanovic D, Medic G, Sovtic DD. Guidelines for pharmacoeconomic evaluation for Serbia. Value Health 2011;14:A358.

6. Nagurney JT, Braham RL, Reader GG. Physician awareness of economic factors in clinical decision-making. Med Care 1979;17:727-36. [CrossRef] 
7. Matthews BA, Baker F, Spillers RL. Healthcare professionals' awareness of cancer support services. Cancer Pract 2002;10:3644. [CrossRef]

8. Jakovljevic MB. Resource allocation strategies in Southeastern European health policy. Eur J Health Econ 2013;14:153-9. [CrossRef]

9. Skootsky SA, Slavin S, Wilkes MS. Attitudes toward managed care and cost containment among primary care trainees at 3 training sites. Am J Manag Care 1999;5:1397-404.

10. IBM Knowledge Center. QUEST Criteria. Available at: http:// www-01.ibm.com/support/knowledgecenter/SSLVMB_20.0.0/ com.ibm.spss.statistics.help/idh_idd_criteria_quest. htm?lang=en.

11. Caroselli C. Economic awareness of nurses: relationship to budgetary control. Nurs Econ 1996;14:292-8.

12. Wieseke A, Bantz D. Economic awareness of registered nurses employed in hospitals. Nurs Econ 1992;10:406-12.

13. Allan GM, Innes G. Family practice residents' awareness of medical care costs in British Columbia. Fam Med 2002;34:104-9.

14. Blendon RJ, Benson JM, Botta MD, Zeldow D, Kim MK. A four-country survey of public attitudes towards restricting healthcare costs by limiting the use of high-cost medical interventions. BMJ Open 2012;2.

15. McGuire C, King S, Roche-Nagle G, Barry MC. Doctors' attitudes about prescribing and knowledge of the costs of common medications. Ir J Med Sci 2009;178:277-80. [CrossRef]

16. Dordevic ND, Jankovic SM. Characteristics of decision-making process during prescribing in general practice. Vojnosanit Pregl 2006;63:279-85. [CrossRef]

17. Jakovljevic M, Biorac N, Markovic V. Patient compliance role in chronic disorders treatment - pharmacoeconomic perspective. Medicinski Casopis 2008;42:57-63.

18. Jansson S, Anell A. The impact of decentralised drug-budgets in Sweden - a survey of physicians' attitudes towards costs and cost-effectiveness. Health Policy 2006;76:299-311. [CrossRef]

19. Reichert S, Simon T, Halm EA. Physicians' attitudes about prescribing and knowledge of the costs of common medications. Arch Intern Med 2000;160:2799-803. [CrossRef]
20. Conti G, dell'Utri D, Pelaia P, Rosa G, Cogliati AA, Gasparetto A. Do we know the costs of what we prescribe? A study on awareness of the cost of drugs and devices among ICU staff. Intensive Care Med 1998;24:1194-8. [CrossRef]

21. Allan GM, Lexchin J. Physician awareness of diagnostic and nondrug therapeutic costs: a systematic review. Int J Technol Assess Health Care 2008;24:158-65.

22. Rankovic A, Rancic N, Jovanovic M, Ivanović M, Gajović O, Lazić Z, et al. Impact of imaging diagnostics on the budget - Are we spending too much? Vojnosanit Pregl 2013;70:709-11.

23. Bailey CR, Ruggier R, Cashman JN. Anaesthesia: cheap at twice the price? Staff awareness, cost comparisons and recommendations for economic savings. Anaesthesia 1993;48:906-9. [CrossRef]

24. Bellian DP, King KA, Wahl J, Price JH. Psychiatrists' knowledge and attitudes about costs of commonly prescribed treatments in psychiatry. J Community Health 2001;26:11-22. [CrossRef]

25. Kuiken T, Prather H, Bloom S. Physician awareness of rehabilitation costs. Am J Phys Med Rehabil 1996;75:416-21. [CrossRef]

26. Toker A, Reuveni H, Perry ZH, Doron Y. [Medical students' knowledge and attitudes towards costs of tests and treatments]. Harefuah 2007;146:22-5.

27. Weng YH, Kuo KN, Yang CY, Lo HL, Chen C, Chiu YW. Implementation of evidence-based practice across medical, nursing, pharmacological and allied healthcare professionals: a questionnaire survey in nationwide hospital settings. Implement Sci 2013;8:112. [CrossRef]

28. Peterson GM, Jackson SL, Fitzmaurice KD, Gee PR. Attitudes of Australian pharmacists towards practice-based research. $J$ Clin Pharm Ther 2009;34:397-405. [CrossRef]

29. Burkiewicz JS, Zgarrick DP: Evidence-based practice by pharmacists: utilization and barriers. Ann Pharmacother 2005;39:1214-9. [CrossRef]

30. Gollust SE, Lynch J. Who deserves health care? The effects of causal attributions and group cues on public attitudes about responsibility for health care costs. $J$ Health Polit Policy Law 2011;36:1061-95. [CrossRef]

APPENDIX 1. Economic Awareness of Healthcare Professionals Questionnaire (EAHPQ-29) English version

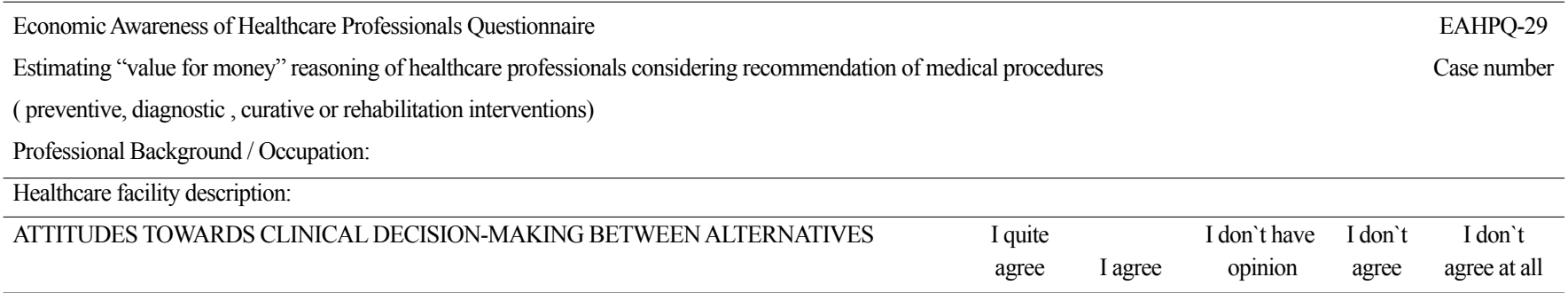

1 Treatment must be prescribed for particular indication only if it is concordant with the officially accepted guidelines.

2 I am familiar if the health authorities have issued guidance which regulates legitimacy of performing the intervention in particular disease.

3 I am familiar with market price of all alternative interventions (preventive, diagnostic test, curative or rehabilitating). 
APPENDIX 1. Economic Awareness of Healthcare Professionals Questionnaire (EAHPQ-29) English version (Continious)

4 I do estimate risk-benefit ratio of all alternative medical interventions considered.

5 I am familiar with cost-effectiveness ratio for each alternative considered.

6 I do know if the recommended medicine or the procedure is currently being reimbursement within ordinary citizen's insurance coverage.

7 I am familiar if there is any additional financial burden for the patient outsourcing from the treatment recommended such as the home care, transportation, job absenteeism or else.

8 I am aware if some of the mentioned costs could be avoided by choosing a different procedure which provides similar health benefit?

9 I do estimate if the expected clinical outcome of each alternative intervention vindicates its appliance.

10 I do consider whether it may be better for the patient not to interfere, observing clinical development.

11 Commonly I am willing to consult additional, evidence based sources about the disputed clinical problem.

12 It seems to me that I have observed an irrational recommendation of procedures lacking firm evidence on efficiency.

\section{ATTITUDES TOWARDS QUALITY OF THE HEALTH CARE}

13 If I could choose I d rather be referred to a private doctor than to a State-owned Health Service.

14 Administration and financial policy in healthcare are considerably involved in the doctor-patient relationship.

15 Administration and financial policy in healthcare are more focused on cost savings than with the provision of quality health care.

16 The doctors in privately-owned facilities are more concerned about their income than with the quality of the healthcare.

17 Physicians employed within State-owned facilities due to strict inner and outer control, run fewer tests and examinations per patient compared to the physicians employed within privately-owned facilities

18 I do have less confidence in fellow physicians employed in State-owned facilities compared to the ones employed within privately-owned facilities

19 The physicians employed within State-owned Institutions don't have the same level of the dedication tothe patients as the physicians in the private sector do agree at all

$\begin{array}{cccc}\begin{array}{c}\text { I quite } \\ \text { agree }\end{array} \quad \text { I agree } & \begin{array}{c}\text { I don`thave } \\ \text { opinion }\end{array} & \begin{array}{c}\text { I don`t } \\ \text { agree }\end{array} & \begin{array}{c}\text { I don`t } \\ \text { agree at all }\end{array}\end{array}$

20 The physicians in the State-owned institutions work fewer hours a day than the physicians in the privately owned institutions.

21 I would avoid prescribing medicines strictly based on instructions of the non-medical management body.

22 Actual changes in our health system diminish the independence of the physicians ever more.

23 The physicians in State-owned Institutions make fewer professional mistakes than those in private-owned institutions.

\section{ATTITUDES TOWARDS COST CONTAINMENT POLICY}

24 The price of some diagnostic test should not affect the decision of the institute whether to obtain it.

25 Even if there is only the minor probability that the test will give the diagnostically useful information, it should be run.

26 If the patient demands certain laboratory analysis or the imaging examination and the risk of harm is acceptable, the patient should be given the service demanded.

27 The medical cost containment is more important than to let the doctors and patients make free agreements about the healing plan.

28 Achieving cost savings within the healthcare is out of reach of the physicians and their professional associations.

29 Routine and detailed validation of the clinical decisions is the reasonable way of decreasing expenditure of the medical facility. 